\title{
A full characterization of Nash implementation with strategy space reduction
}

Citation for published version (APA):

Lombardi, M., \& Yoshihara, N. (2010). A full characterization of Nash implementation with strategy space reduction. METEOR, Maastricht University School of Business and Economics. METEOR Research Memorandum No. 023 https://doi.org/10.26481/umamet.2010023

Document status and date:

Published: 01/01/2010

DOI:

10.26481/umamet.2010023

Document Version:

Publisher's PDF, also known as Version of record

\section{Please check the document version of this publication:}

- A submitted manuscript is the version of the article upon submission and before peer-review. There can be important differences between the submitted version and the official published version of record.

People interested in the research are advised to contact the author for the final version of the publication, or visit the DOI to the publisher's website.

- The final author version and the galley proof are versions of the publication after peer review.

- The final published version features the final layout of the paper including the volume, issue and page numbers.

Link to publication

\footnotetext{
General rights rights.

- You may freely distribute the URL identifying the publication in the public portal. please follow below link for the End User Agreement:

www.umlib.nl/taverne-license

Take down policy

If you believe that this document breaches copyright please contact us at:

repository@maastrichtuniversity.nl

providing details and we will investigate your claim.
}

Copyright and moral rights for the publications made accessible in the public portal are retained by the authors and/or other copyright owners and it is a condition of accessing publications that users recognise and abide by the legal requirements associated with these

- Users may download and print one copy of any publication from the public portal for the purpose of private study or research.

- You may not further distribute the material or use it for any profit-making activity or commercial gain

If the publication is distributed under the terms of Article $25 \mathrm{fa}$ of the Dutch Copyright Act, indicated by the "Taverne" license above, 


\section{Maastricht University}

Michele Lombardi, Naoki Yoshihara

A Full Characterization of Nash I mplementation with Strategy Space Reduction

RM/ 10/023

\section{METEOR}

Maastricht University School of Business and Economics

Maastricht Research School of Economics

of Technology and Organization

\section{P.O. Box 616}

NL - 6200 MD Maastricht

The Netherlands 


\title{
A Full Characterization of Nash Implementation with Strategy Space Reduction ${ }^{\infty}$
}

\author{
M ichele Lombardiy and Naoki Yoshiharaz \\ A pril 26, 2010
}

\begin{abstract}
A bstract
Noting that a full characterization of Nash-implementation is given using a canonical-mechanism and M askin's theorem (M askin, 1999) is shown using a mechanism with Saijo's type of strategy space reduction (Saijo, 1988), this paper fully characterizes the class of Nashimplementable social choice correspondences (SCCs) by mechanisms with the strategy space reduction, which is further shown to be equivalent to the class of Nash-implementable SCCs.
\end{abstract}

J EL classification: C72; D71; D82.

K eywords: Nash implementation, strategy space reduction, s-mechanisms, Condition $1 \mathrm{~s}$

${ }^{x}$ This paper was started when Lombardi was a COE Visiting Young Researcher at Hitotsubashi University. Their generous hospitality and financial support is gratefully acknowledged.

YDepartment of Q uantitative E conomics, $M$ aastricht School of B usiness and $E$ conomics, M aastricht University, P.O. B ox 616, NL-6200 M D M aastricht, Netherlands, phone: (+31) 43388 3761; fax: (+31) 43388 4874, e-mail: m.lombardi@maastrichtuniversity.nl.

${ }^{z}$ (Corresponding A uthor) Institute of Economic R esearch, Hitotsubashi University, 2-4 Naka, K unitachi, Tokyo, 186-8603 J apan, phone: (+81) 42580 8354, fax: (+81) 42580 8333, e-mail: yosihara@ier.hit-u.ac.jp. 


\section{Introduction}

In Nash implementation theory, it is M askin's T heorem (M askin, 1999) which shows that when the planner faces at least three agents, a social choice correspondence (SCC) is implementable in (pure-strategy) Nash equilibria (henceforth, Nash-implementable) if it satisfies Maskin monotonicity and no-veto power; conversely, any Nash-implementable SCC is Maskin-monotonic. T wo issues pertaining to this theorem stand out. First, it does not provide a complete characterization of N ash-implementable SCCs, since no-veto power is not necessary for Nash implementation. Second, a canonical mechanism proposed in this theorem, which requires each agent to report a preference profile, a feasible social outcome, and an integer, is not so attractive. This is because the message space of this mechanism is rather large and announcing all other agents' preferences is undesirable in terms of the informational ec ciency of decentralized decision making (on this point see, for instance, Hurwicz, 1960).

M oore and Repullo (1990) address the first issue by providing, without any domain restriction, a necessary and suф cient condition, called Condition ${ }^{1}$, for Nash implementability of SCCs in societies with more than two agents. ${ }^{1}$ In contrast to the first issue, the issue of informational ed ciency is addressed by Saijo (1988), which shows that proposing a mechanism with strategy-space reduction (henceforth, s-mechanism) would suc ce to guarantee Maskin's Theorem. Note that, in s-mechanisms, each agent is requested to announce, in addition to a feasible social outcome and an integer, her own and her neighbor's preferences solely. Yet, as Moore and R epullo (1990) also use a canonical mechanism for showing the full characterization and Saijo (1988) does not discuss a full characterization of Nash implementation, it leaves unclear not only whether Moore and Repullo's result indispensably relies on canonical mechanisms but also whether s-mechanisms can Nashimplement any other SCC than Maskin-monotonic and no-veto power ones.

In this paper, we address the issue of what constitutes the necessary and suc cient condition for Nash implementation by s-mechanisms. We introduce a new condition (labelled, Condition ${ }^{1 \mathrm{~s}}$ ) which fully characterizes the class

\footnotetext{
${ }^{1}$ Note that, for two person societies, Moore and Repullo (1990) and Dutta and Sen (1991) independently provided necessary and suc cient conditions for Nash implementation, whereas even in societies with more than two agents, there are other works on complete characterizations of $\mathrm{Nash}$ implementation under some domain restrictions, such as Danilov (1992) and Yamato (1992).
} 
of SCCs Nash-implemantable by s-mechanisms. Surprisingly, Condition ${ }^{1} \mathrm{~s}$ is equivalent to Condition ${ }^{1}$. This implies that the full characterization by M oore and Repullo (1990) works even if canonical mechanisms are excluded and the available class of mechanisms is restricted to that of s-mechanisms.

The paper is organized as follows. In section 2, we introduce notation and definitions. In Section 3, we state and prove our results.

\section{Preliminaries}

The set of (social choice) environments is $\left(N ; X ; R^{n}\right)$, where $N^{\prime} f 1 ;:: ;$, ng is a set of $n, 3$ agents, $X^{\prime} \quad f x ; y ; z ;:: g$ is the set of attainable alternatives (or outcomes), and $\mathrm{R}^{\mathrm{n}}$ is the set of admissible preference profiles (or states of the world). Henceforth, we assume that the cardinality of $X$ is $\# X, 2$. Let $R(X)$ be the set of all complete preorders on $X$. We assume that $R^{n}$ ' $R_{1} f::: f R_{n}$ is a non-empty subset of the $n$-fold Cartesian product $R^{n}(X)$ '

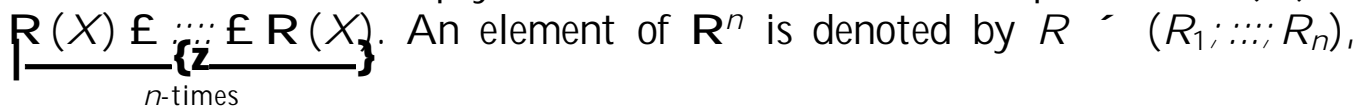
where its '-th component is $R \cdot 2 \mathrm{R}$, for each ' $2 \mathrm{~N}$. For any preference profile $R 2 R^{n}$ and any ' $2 N$, let $R_{i}$ ' be the list of elements of $R$ for all agents except ', i.e., $R_{i}$ '’ $\left(R_{1} ; \ldots ; R_{{ }_{i} 1} ; R_{{ }_{+}+1} ; \ldots ; R_{n}\right)$. Given a list $R_{i}$ ' and $R \cdot 2 R$, we denote by $\left(R_{i} \cdot ; R \cdot\right)$ the preference profile consisting of these $R$. and $R_{i}$ '. For any $(R ; x) 2 R \cdot f X$, agent ''s weakly lower contour set of $R$. at $x$ is given by $L(R ; x)$ ' fy $2 x j(x ; y) 2 R \cdot g$. For each ' $2 N$ and each R. $2 R$. $\max _{R} \cdot X^{\prime} f \times 2 \times j(x ; y) 2 R$. for all y $2 \times g$.

We also assume that $N$ and $X$ are fixed throughout the following discussion, so that the set of environments is boiled down to $R^{n}$. A social choice correspondence $(S C C)$ is a correspondence $F: R^{n}{ }^{3} \quad X$ with $F(R) G$ ? for all $R 2 R^{n}$. An SCC $F$ is (Maskin-)monotonic if, for all $R ; R^{0} 2 R^{n}$ with $x 2 F(R)$, we have that $\times 2 F\left(R 9\right.$ whenever $L(R ; x) \mu L\left(R^{0} ; x\right)$ for all $2 N{ }^{2}$ An SCC $F$ satisfies no-veto power if, for all $R 2 R^{n}$, we have that $\times 2 F(R)$ whenever $\times 2 \max _{R} . X$ for at least $n ; 1$ agents.

A mechanism (or game-form) is a pair $\infty^{\prime}(M ; g)$, where $M{ }^{\prime} M_{1} f$ $::: \mp M_{n}$, and $g: M$ ! $X$ is the outcome function. Denote a generic message (or strategy) for agent ' by $m \cdot 2 \mathrm{M}$ - and a generic message profile by $m=\left(m_{1} ;:: ; m_{n}\right) 2 M$. For any $m 2 M$ and ' $2 N$, let $m_{i}$. $\left(m_{1} ; \ldots ; m_{i} ; m_{+1} ;: ; ; m_{n}\right)$. Let $M_{i}$ ' $f_{j 2 N n f}{ }^{\prime} M_{j}$. Given $m_{i} \cdot 2 M_{i}$, and

\footnotetext{
${ }^{2}$ Weak set inclusion is denoted by $\mu$.
} 
$m \cdot 2 M$, denote by $\left(m ; m_{i}\right)$ the message profile consisting of these $m$ and $m_{i}$. Given $R 2 R^{n}$ and $\infty=(M ; g),(\infty ; R)$ constitutes a (non-cooperative) game. Given a game $(\infty, R), m 2 M$ is a (pure strategy) Nash equilibrium of $(\infty, R)$ if and only if, for all $2 \mathrm{~N},\left(\mathrm{~g}(\mathrm{~m}) ; g\left(\mathrm{~m}^{0} ; \mathrm{m}_{\mathrm{i}} \cdot\right)\right) 2 \mathrm{R}$. for all $\mathrm{m}^{0} 2 \mathrm{M}$. Let $N E(\infty, R)$ denote the set of $N$ ash equilibria of $(\infty, R)$, whereas denote the set of $N$ ash equilibrium outcomes of $(\infty, R)$ by $N A(\infty, R)^{\prime} g(N E(\infty, R))$.

A mechanism $\infty=(M ; g)$ implements $F$ in Nash equilibria, or simply Nash-implements $F$, if and only if $N A(\infty, R)=F(R)$ for all $R 2 R^{n}$. An SCC $F$ is Nash-implementable if there is such a mechanism.

Moore and Repullo (1990) show that, under the society with more than two agents, the following condition is the necessary and suc cient condition for any SCC to be Nash-implemetable.

Condition ${ }^{1}$ (for short, ${ }^{1}$ ): An SCC $F$ satisfies ${ }^{1}$ if there exists a set $Y \mu X$, and for all $R 2 R^{n}$ and for all $\times 2 F(R)$, there is a profile of sets $(C \cdot(R ; x))_{2 N}$ such that $x 2 C \cdot(R ; x) \mu L(R ; x) \backslash Y$ for all ${ }^{`} 2 N$, and for any $R^{x} 2 R^{n}$ :

(i) if $C \cdot(R ; x) \mu L\left(R^{x} ; x\right)$ for all ' $2 N$, then $x 2 F\left(R^{x}\right)$;

(ii) for each i $2 N$, if y $2 C_{i}(R ; x) \mu L\left(R_{i}^{x} ; y\right)$ and $Y \mu L\left(R^{x} ; y\right)$ for all $2 \mathrm{Nnfig}$, then y $2 \mathrm{~F}\left(\mathrm{R}^{\mathrm{x}}\right)$;

(iii) if y $2 Y \mu L\left(R^{x} ; y\right)$ for all $2 N$, then y $2 F\left(R^{\natural}\right)$.

\section{R esults}

Following Saijo (1988), we focus on mechanisms in which each agent reports her own preference $R \cdot 2 R_{\text {, }}$, her neighbor's preference $\mathbf{R}_{++1} 2 \mathbf{R}_{{ }_{+}+1}$, an outcome $\times 2 \mathrm{Y} \mu \mathrm{X}$, and an integer $\mathrm{k} 2 \mathrm{~N}$.

Definition 1: A mechanism $(\mathrm{M} ; \mathrm{g})$ is s-mechanism if, for any ' $2 \mathrm{~N}$,

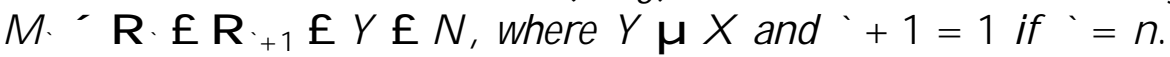

Definition 2: An SCC $F$ is Nash-implementable by an s-mechanism if there exists an $\mathrm{s}$-mechanism $(\mathrm{M} ; \mathrm{g})$ such that:

i) for all $R 2 R^{n}, F(R)=N A(\infty, R)$; and

ii) for all $R 2 R^{n}$ and all $\times 2 F(R)$, if $m={ }^{i} R ; R+1 ; x ; k^{\prime \$} 2 M$. for all ${ }^{\prime} 2 \mathrm{~N}$, with ${ }^{`}+1=1$ if $`=\mathrm{n}$, then $\mathrm{m} 2 \mathrm{NE}(\infty, \mathrm{R})$ and $\mathrm{g}(\mathrm{m})=\mathrm{x}$.

We now introduce a condition, labelled Condition ${ }^{1 \mathrm{~s}}$, to characterize Nash implementability by s-mechanisms. The condition can be stated as follows. 
Condition ${ }^{1 \mathrm{~s}}$ (for short, ${ }^{1 \mathrm{~s}}$ ): A $\mathrm{n}$ SCC $\mathrm{F}$ satisfies condition ${ }^{1 \mathrm{~s}}$ if there exists a set. $Y \mu X$, and fofall $R 2 R^{n}$ and for all $\times 2 F(R)$, there is a profile of sets ${ }^{\prime} C^{\prime} \cdot{ }^{\prime} R_{i} f^{\prime} ;+1 g ; X^{4}{ }^{2}$ such that $x 2 C^{\prime} \cdot{ }^{\prime} R_{i} f^{\prime} ;+1 g ; X^{4} \mu L(R ; x) \backslash Y$ for

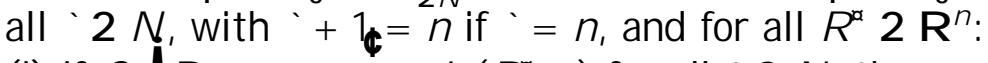

(i) if $C \cdot R_{i} f^{\prime} ;+1 g ; x^{4} \mu L\left(R^{p} ; x\right)$ for afl $2 N$, then $\times 2 F\left(R^{x}\right)$;

(ii) for all i $2 \mathrm{~N}$, if y $2 C_{i} R_{i}$ fi;i+1g; $x \mu L\left(R_{i}^{p} ; y\right)$ and $Y \mu L\left(R^{p} ; y\right)$ for all $2 \mathrm{Nnfig}$, then y $2 \mathrm{~F}\left(\mathrm{R}^{\mathrm{x}}\right)$;

(iii) if y $2 Y \mu L\left(R^{x} ; y\right)$ for all $` 2 N$, then y $2 F\left(R^{x}\right)$.

Proposition 1. An SCC F satisfies ${ }^{1 \mathrm{~s}}$ if it is Nash-implementable by an s-mechanism.

Proof. Let an SCC F be Nash-implementable by an s-mechanism. Then, since it is Nash-implementable, it satisfies ${ }^{1}$. Thus, there exists a set $Y \mu$ $X$, and for all $R 2 R^{n}$ and for all $\times 2 F(R)$, there is a profile of sets $(C \cdot(R ; x))_{2 N}$ such that $x 2 C \cdot(R ; x) \mu L(R ; x) \backslash Y$ for all ${ }^{`} 2 N$. Moreover, for any $R^{x} 2 R_{i}^{n},{ }^{1}$ (i)-(iii) are satisfied. Now, for each $R 2 R^{n}$ and each $x 2$ $F(R)$, let ' $C \cdot R_{i} f^{\prime} ;{ }^{\prime}+1 g ; X^{4}{ }_{2 N}$ be defined as $C^{\prime}{ }^{\prime} R_{i} f^{\prime} ;+1 g ; x^{4}$ ' $C \cdot(R ; x)$ for each ` $2 \mathrm{~N}$. Then, $\mathrm{F}$ satisfies ${ }^{1 \mathrm{~s}}$.

Proposition 2. An SCC F satisfying ${ }^{1 \mathrm{~s}}$ is $\mathrm{N}$ ash-implementable by an $\mathrm{s}$ mechanism.

Proof. Let $\infty^{\prime}(M ; g)$ be an s-mechanism. Suppose that $F$ satisfies ${ }^{15}$.

Fix any $m 2 M, R 2 R^{n}$, and $x 2 x$, and let $m=R^{i} ; R_{+1}^{i} ; x^{\prime} ; k^{i \Phi} 2$ $M$, where ${ }^{`}+1=1$ if ${ }^{`}=n$, and where the announcement of agent ${ }^{`} 2 \mathrm{~N}$ about agent ${ }^{\prime}+1$ 's preferences is $R^{\prime}{ }_{+1}$. We say that the message profile $\mathrm{m} 2 \mathrm{M}$ is:

(i) consistent with $\mathrm{R}$ and $\mathrm{x}$ if, for all ${ }^{\prime} 2 \mathrm{~N}, \mathrm{R} \backslash=\mathrm{R} \cdot \mathrm{i}^{1}=\mathrm{R}$. and $\mathrm{x}^{\prime}=\mathrm{x}$, where ' $\mathrm{i} 1=\mathrm{n}$ if ${ }^{\prime}=1$;

(ii) $m_{i}$ i quasi-consistent with $x$ and $R$, where i $2 \mathrm{~N}$, if for all ' $2 \mathrm{~N}, \mathrm{x}^{\prime}=\mathrm{x}$, and for all ' $2 \mathrm{Nnf} i ; i+1 g, R^{`}=R^{\prime}{ }^{\prime 1}=R \cdot R_{i}^{i{ }^{i}}=R_{i}, R_{i+1}^{i+1}=R_{i+1}$, and $\left[R_{i}^{i} \in R_{i}\right.$ or $\left.R_{i}^{i} \in R_{i+1}\right]$, where $j$ i $1=n$ if $j=1$ for $j 2 \mathrm{fi}$; ' ;

(iii) $m_{i}$ c consistent with $x$ and $R$, where i $2 \mathrm{~N}$, if for all ' $2 \mathrm{Nnfig}, x^{\prime}=x \epsilon$ $x^{i}$, and for all ' $2 \mathrm{Nnfi} ; i+1 g, R^{\prime}=R^{\prime i 1}=R^{\prime}, R_{i}^{i j}=R_{i}$ and $R_{i+1}^{i+1}=R_{i+1}$, where $\mathrm{j} i \mathrm{l}=\mathrm{n}$ if $\mathrm{j}=1$ for $\mathrm{j} 2 \mathrm{fi}$; $\mathrm{g}$.

Define the outcome function $\mathrm{g}: \mathrm{M} ! \mathrm{X}$ as follows: For any $\mathrm{m} 2 \mathrm{M}$, Rule 1: $m$ is consistent with $x$ and $R 2 R^{n}$, where $x 2 F^{i} R^{\phi}$, then $g(m)=x$. 
R ule 2: For some i $2 \mathrm{~N}, \mathrm{~m}_{\mathrm{i}}$ i is quasi-consistent with $\mathrm{x}$ and $\mathrm{R} 2 \mathrm{R}{ }^{\mathrm{n}}$, where $\times 2 F^{1} R^{4}$, then $g(m)=x$.

Rule 3: Eor some i $2 \mathrm{~N}, \mathrm{~m}$ is $\mathrm{m}_{\mathrm{i}}$ i consistent with $x$ and $R 2 \mathrm{R}$, where $\times 2 F^{i}{ }^{\top}$, and $C_{i}{ }^{i} R_{i} f i ; i+1 g ; x \in Y$, then

$$
g(m)={ }_{x}^{1 / 2} x^{i} \text { if } \quad x^{i} 2 C_{i}{ }^{i} R_{i f i ; i+1 g} ; x^{\Phi} .
$$

R ule 4: Otherwise, $g(m)=x^{، x}(m)$ where ${ }^{` x}(m){ }_{i 2 N}{ }^{P} k^{i}(\bmod n) .^{3}$

Since $F$ satisfies ${ }^{1 \mathrm{~s}}$, it follows that, for any $R 2^{i 2 \mathrm{~N}} \mathrm{R}^{\mathrm{n}}$ and any $\times 2 \mathrm{~F}(\mathrm{R})$, $x 2 \mathrm{Y}$. We show that $\infty=(\mathrm{M} ; \mathrm{g})$ Nash-implements $\mathrm{F}$. For, let $\mathrm{R} 2 \mathrm{R}^{\mathrm{n}}$.

To show that $F(R) \mu N A(\infty, R)$, let $\times 2 F(R)$ and suppose that, for all

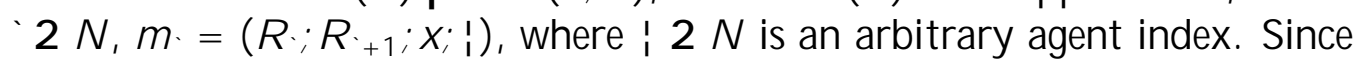
$m$ is consistent with $x$ and $R$ and $x 2 F(R)$, it follows from Rule 1 that $g(m)=x$. Suppose that ' $2 N$ deviates from $m$ to $m^{\alpha}={ }^{1}{ }^{\prime} ; R_{i+1} ; x_{;} ;{ }^{4} 2$ $M$. such that $\left(R_{\cdot} ; R_{+1} ; x\right) \in R_{i} ; R_{i+1} ; x^{\prime}$. It follows from $R$ ules $2-3$ that

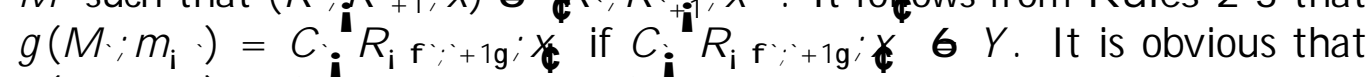
$g\left(M ; m_{i} \cdot\right) \mu C \cdot R_{i} f^{\prime} ;+1 g ; x$ if $C \cdot R_{i} f^{\prime} ;+1 g ; x=Y$. Since $F$ satisfies ${ }^{1} s$, it follows that $g\left(M_{\cdot} ; m_{i} \cdot\right) \mu L(R ; x)$. As it holds for any ${ }^{\prime} 2 N$, we have m $2 N E(\infty, R)$ and so $\times 2 N A(\infty, R)$. Furthermore, this guarantees the condition (ii) of Definition 2.

Conversely, to show that $N A(\infty, R) \mu F(R)$, let $m 2 N E(\infty, R)$. Consider the following cases.

Case 1: $\mathrm{m}$ falls into Rule 1.

Then, $m$ is consistent with $x$ and $R 2 R^{n}$, where $x 2_{4} F^{i_{R}}{ }^{\$}$. Thus, $g(m)=x$. Take apy $2 N$. Suppose that $C \cdot{ }^{\prime} R_{i f} ;+1 g \phi^{x} \in Y$. For any y $2 C \cdot{ }^{1} R_{i f}{ }^{\prime} ;+g ; x$, changing $m$ for $m^{\alpha}={ }^{i}{ }^{\prime} ; R_{i+1} ; y ; l^{2}{ }^{M}$. agent can

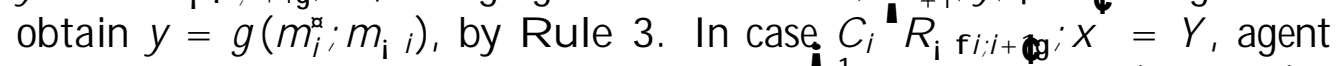
can attain any y $2 Y$ by $R$ ule 4 . Thus, $C \cdot{ }^{1} R_{i f f}{ }^{\prime} ;+1 g ; x=g\left(M ; m_{i} \cdot\right)$ for

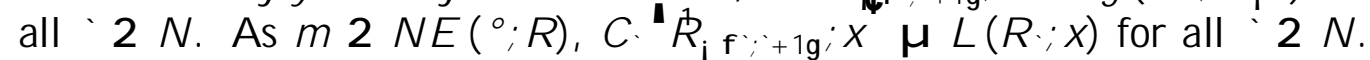
Therefore, $x 2 \mathrm{~F}(\mathrm{R})$ by ${ }^{1 \mathrm{~s}}(\mathrm{i})$.

Case 2: $\mathrm{m}$ falls into Rule 2.

Then $m$ is $m_{i}$ i quasi-consistent with $x$ and $R 2 R^{n}$, where $x 2 F^{i}{ }^{\phi}$. Thus, $g(m)=x$. We proceed according the following sub-cases: 1$) R_{i} \in R_{i}$ and $R_{i}^{i} \in R_{i+1}$, and 2) $R_{i}^{i} \in R_{i}$ and $R_{i}^{i}=R_{i+1} \cdot{ }^{4}$

\footnotetext{
${ }^{3}$ If the remainder is zero the winner of the game is agent $n$.
} 
Sub-case 2.1. $R_{i}^{i} \in R_{i}$ and $R_{i}^{i} \in R_{i+1}$

A ny ' $2 \mathrm{Nnfig}$ can attain any y $2 \mathrm{Ynfxg}$ by inducing Rule 4 , so that $\times 2 \max _{R}, Y$ as $m \& N E(\infty, R)$. Take any y $2 C_{i}{ }^{\prime} R_{i}$ fi; $i+1 g ; x$. Suppose

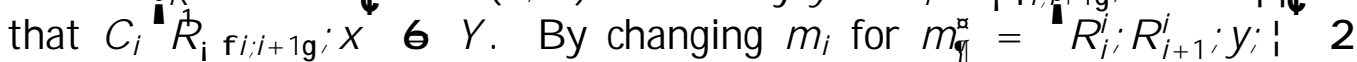
$M_{i_{i}}$ agent $i$ cap obtain $y=g\left(m_{i}^{\natural} ; m_{i}\right)$, by Rule 3 . In the case that $C_{i} R_{i f i ; i+1 g} ; X=Y$, by changing $m_{i}$ for $m_{i}^{a}=R_{i}^{i} ; R_{i+1}^{i} ; y ; k^{i} 2 M_{i}$ agent $\mathrm{i}$ can attain $\mathrm{y}=g\left(\mathrm{~m}_{\mathrm{i}}^{\mathrm{z}} ; \mathrm{m}_{\mathrm{i}}\right)$ by appropriately choosing $\mathrm{k}^{\mathrm{i}}$. It follows that $C_{i}{ }^{\prime}{ }^{2}{ }_{i} f i ; i+g ; x^{4} \mu g\left(M_{i} ; m_{i}\right)$. Moreover, as $m 2 N E(\infty ; R)$, $C_{i}{ }^{\prime} R_{i}$ fi;i+1g; $x \mu L\left(R_{i} ; x\right)$. Therefore, $x 2 F(R)$ by either ${ }^{1 s}$ (ii) or ${ }^{1 s}($ iii). Sub-case 2.2. $R_{i}^{i} \in R_{i}$ and $R_{i+1}^{i}=R_{i+1}$

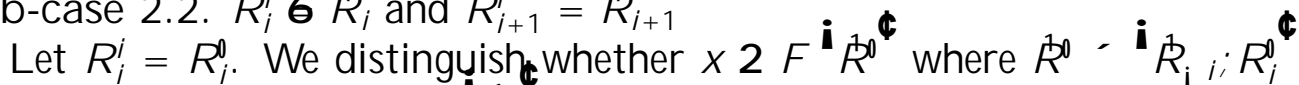
or not. Suppose that $x Z F^{1} R^{0}$. Then the same reasoning used above for sub-case 2.1 carries over into this sub-case, so that $\times 2 \mathrm{~F}(\mathrm{R})$. Otherwise, let $\times 2 \mathrm{~F}^{1} \mathrm{R}^{0}$. Then, $\mathrm{i} i \mathrm{l}$ or $\mathrm{i}$ is the deviator. A gent $2 \mathrm{Nnfi} i \mathrm{i} ; \mathrm{ig}$ can attain any y 2 Y nfxg by inducing Rule 4, so that $\times 2 \max _{R} . Y$ as $m 2 N E(\infty, R)$. Since $x 2 F^{\prime} R^{2}$, there exists $C \cdot{ }^{\prime} R_{i} f^{\prime} ;+1 g ; x \mu Y$ for each ' $2 \mathrm{Nnfi} i \mathrm{i} ; \mathrm{ig}$, and so $\mathrm{C}^{\prime} \mathrm{i}_{\mathrm{R}_{\mathrm{i}}{ }^{\prime} ;+1 \mathrm{~g} ; \mathrm{X}} \mu \mathrm{L}(\mathrm{R} ; \mathrm{x})$ by $\mathrm{Y} \mu$ $L\left(R_{r} ; x\right)$ for each ' $2 \mathrm{Nnfi}_{i} 1 ; i g$. Observe that $R_{i \text { fiji } i+1 g}=R_{i}^{0} f_{i j i+1 g}$

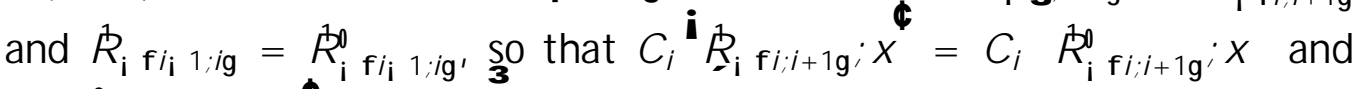

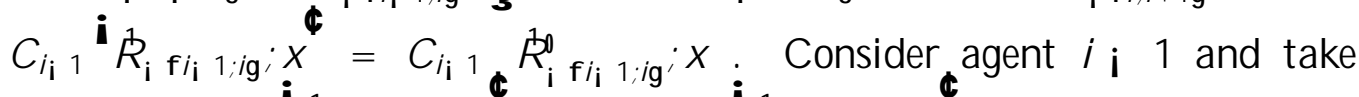

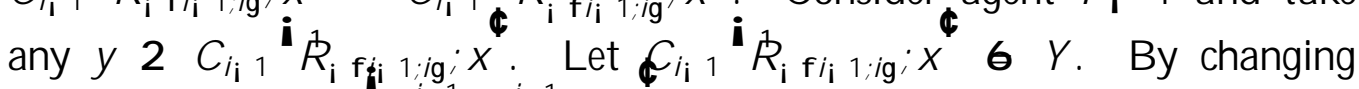

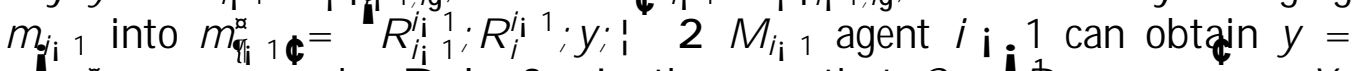

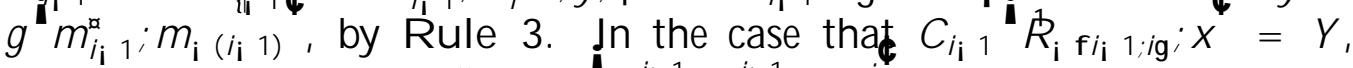

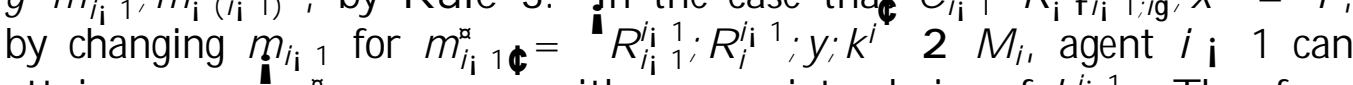
attaig $y=g m_{i j}^{\alpha} ; m_{i}\left(i_{i} 1\right)$ with appropriate choice of $k^{i_{i}{ }^{1}}$. Therefore, $C_{i_{i} 1} R_{i f i_{i} 1 ; i g}^{0} \times \mu g^{i} M_{i_{i} 1} ; m_{i\left(i_{i} 1\right)}$. By the same reasoning, we have that $C_{i}{ }^{i} R_{i}$ fi;i i $19 ; x \mu g\left(M_{i} ; m_{i}\right)$. Moreover, it follows from $m 2 N E(\infty, R)$

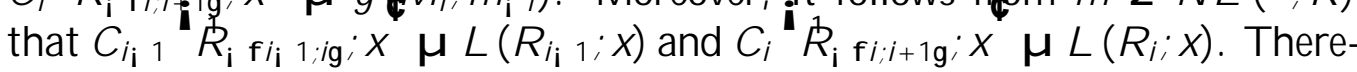
fore, $\times 2 \mathrm{~F}(\mathrm{R})$ by ${ }^{1 \mathrm{~s}}(\mathrm{i})$.

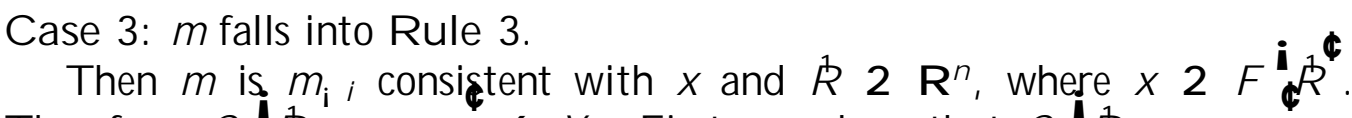
Therefore, $C_{i}{ }^{1} R_{i f i ; i+1 g} ; x^{4} G_{Y} Y$. First $t_{\phi}$ we show that $C_{i}{ }^{1} R_{1} f_{i j i+1 g} ; x^{4} \mu \phi$ $g\left(M_{i} ; m_{i}\right)$. For any $x^{i} 2 C_{i}{ }^{\prime} R_{i} f i ; i+1 g ; x$ nf $x g$, consider $m_{i}^{\alpha}=R_{i}^{i} ; R_{i+1}^{i} ; x^{i} ; l^{4}$.

\footnotetext{
${ }^{4} T$ he sub-case $R_{i}^{i}=R_{i}$ and $R_{i+1}^{i} \in R_{i+1}$ is not explicitly considered as it can be proved similarly to the sub-case 2.2 shown below.
} 
Then, R ule 3 implies that $g\left(m_{i} ; ; m_{i}^{\alpha}\right)=x^{i}$. On the other hand, to attain $x$ agent $i$ can induce Rule 1 by changing $m_{i}$ to $m_{i}^{\alpha}={ }^{\alpha} k_{i} ; R_{i+1} ; x ; i$ so that $g\left(m_{i} ; m_{i}^{\alpha}\right)=x$. Hence, $C_{i}{ }^{\prime} R_{i} f i ; i+1 g ; x^{4} \mu g\left(M_{i} ; m_{i j}\right)$.

Next, we claim that $g\left(M ; ; m_{i}{ }^{\prime}\right)=Y$ for any $2 \mathrm{Nnfig}$. We proceed according to whether $\# \mathrm{Y}=2$ and $\mathrm{n}=3$ or not.

Sub-case 3.1. not[ $\# \mathrm{Y}=2$ and $n=3]$

Suppose that \# $\mathrm{Y}>2$. Take any ` $2 \mathrm{~N}$ nfig. Then, agent `can induce the modulo game by $y_{C}$ choosing any y $2 \mathrm{Ynf} ; \mathrm{x}^{i} \mathrm{~g}$ and changing $\mathrm{m}$ into $m^{\alpha}={ }^{\prime} R^{\prime} ; R^{\prime}{ }_{+1} ; y ; k^{\prime}$. To attain $y$ agent ' has only to adjust $k$ ' by which ${ }^{\prime}{ }^{\prime \prime}\left(m_{i} \cdot ; m^{\natural}\right)={ }^{\prime}$. To attain $x\left(\right.$ resp., $\left.x^{i}\right)$ agent ' has only to adjust $k$ ' by which

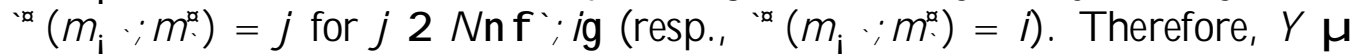

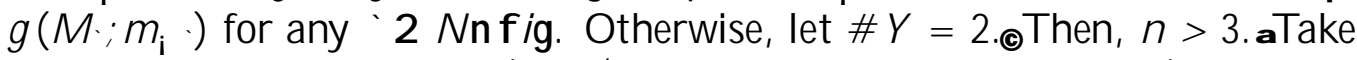
any ' ${ }^{\mathbb{C}} \mathrm{N}$ nfig. Choôsing $\mathrm{x}$ ' $=\mathrm{x}^{\mathrm{i}}$, agent ' can make \# $2 \mathrm{Njx}=\mathrm{x}, 2$ and \# $2 \mathrm{Njx} \in \mathrm{X}, 2$. As the outcome is determined by Rule 4 agent 'can attain any outcome in $\mathrm{Y}$ by appropriately choosing $\mathrm{k}$ '. Therefore, $Y \mu g\left(M ; m_{i} \cdot\right)$ for any ` $2 \mathrm{Nnfig}$.

Sub-case 3.2. $\# Y=2$ and $n=3$

Then, let $\mathrm{N}=\mathrm{fi} ; 1 ; i ; j+1 \mathrm{~g}$ with $\mathrm{i}+1=1$ if $\mathrm{i}=\mathrm{n}$ and $\mathrm{i} i 1=\mathrm{n}$ if $i=1$. As $C_{i}{ }^{i}{ }_{i} f i ; i+1 g ; X \in Y$, it follows that $g(m)=x$. We proceed

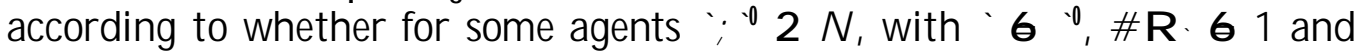
\# R 061 or not.

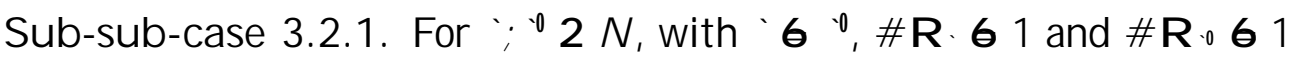

In this case, agent $i_{\text {i }} 1$ (resp., $i+1$ ) can always induce the modulo game by appropriately changing the announcement of her own preference or that of her successor and by carefully choosing the outcome announcement. Finally, to attain $x^{i}$, agent $i \mathrm{i} 1$ (resp., $\left.i+1\right)$ has only to adjust the integer index so that agent $\mathrm{i}$ becomes the winner of the modulo game.

Sub-sub-case 3.2.2. For some ${ }^{\prime}{ }^{0} 2 \mathrm{~N}$, with ${ }^{\prime} \epsilon^{{ }^{\circ}}, \# \mathrm{R} \cdot=1$ or $\# \mathrm{R} \cdot 0=1$

Suppose that, for all ' $2 \mathrm{fi}_{\mathrm{i}} 1 ; \mathrm{i} ; \mathrm{i}+1 \mathrm{~g}, \mathrm{C} \# \mathrm{R}$ : $=1$. As $\mathrm{m}$ falls into Rule 3, it follows that $\times 2 \mathrm{~F}(\mathrm{R})=\mathrm{F} R$. Otherwise, let us consider the case that, for some " $2 \mathrm{fi}^{\prime} 1 ; \mathrm{i} ; \mathrm{i}+1 \mathrm{~g}, \# \mathrm{R}$. 61 . If either $\# R_{i_{i} 1}>1$ or $\# R_{i}>1$, then agent $i i_{1} 1$ can induce the modulo game by

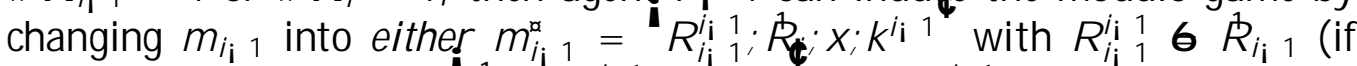

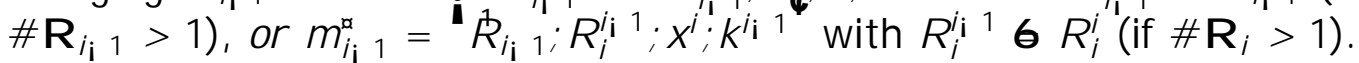
To attain $x^{i}$, agent $\dot{\phi}_{i} 1$ has only to choose an appropriate $k^{i i}{ }^{1}$ so that

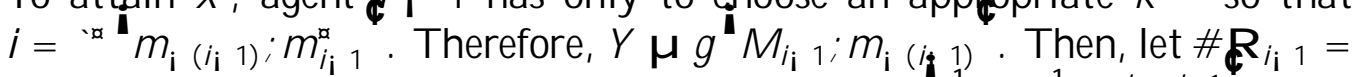
$\# R_{i}=1$. A gent $i_{i} 1$ can change $m_{i j}$ into $m_{i j 1}^{x}=R_{i j} ; R_{i} ; x^{i} ; k^{i i 1}{ }^{2}$. Sup- 
pose that $x^{i} z F^{i} R_{i_{i} 1} ; R_{i} ; R_{i+1}^{i} \stackrel{\$}{~}$. Then, Rule 4 applies, and agept $i i_{1} 1$

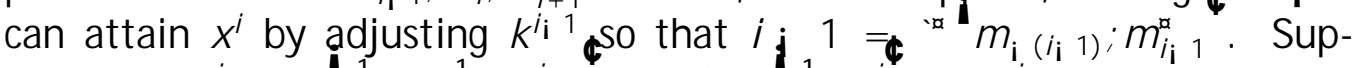
pose that $x^{i} 2 E^{\prime}{ }^{1} R_{i j} ; R_{i} ; R_{i+1}^{i}$. If $C_{i+1} R_{i} ; x^{i^{i}}={ }_{\phi} f x^{i} g$, Rule 3 implies $g^{1} m_{i(i, 1)} ; m_{i j}^{\alpha}=x^{i}$. In the case that $C_{i+1} R_{i} ; x^{i}=Y$, the outcome is determined by $R$ ule 4 , so that by adjusting $k^{i}{ }^{1}$ agent $i{ }_{i} 1$ can attain $x^{i}$. By similar reasoning, it can be shown that agent $i+1$ can attain $x^{i} 2 Y$. Therefore, $Y \mu g\left(M ; m_{i}{ }^{\prime}\right)$ for ${ }^{`} 2 \mathrm{fi} \mathrm{i} 1 ; i+1 \mathrm{~g}$.

In all sub-cases, we obtained $Y \mu g\left(M \cdot m_{i} m^{\prime}\right)$ for all ' $2 \mathrm{Nnfig.} \mathrm{As}$ m $2 \mathrm{NE}(\infty, R)$, we have that $C_{i} R_{i} f ; i+1 g ; x \mu L\left(R_{i} ; g(m)\right)$ and $g(m) 2$ $\max _{R} . Y$ for any $2 \mathrm{Nnfig}$, so that $g(\mathrm{~m}) 2 \mathrm{~F}(\mathrm{R})$ by ${ }^{1} \mathrm{~s}(\mathrm{ii})$.

Case 4: $\mathrm{m}$ falls into Rule 4.

Then the outcome is determined by the modulo game so that $\mathrm{g}(\mathrm{m})=$ $x^{\prime x}(m)$, where agent ${ }^{\prime}(m) 2 N$ is the winner of the modulo game. Thus, $Y \mu g\left(M ; m_{i} \cdot\right)$ for ' $2 N$. Since $m 2 N E(\infty, R)$, it follows that $g(m) 2$ $\max _{R} . Y$ for ${ }^{\prime} 2 \mathrm{~N}$. Therefore, $g(m) 2 F(R)$ by ${ }^{1 \mathrm{~s}}(\mathrm{iii})$.

From the above propositions, we obtain the following main theorem.

Theorem. An SCC F is Nash-implementable by an s-mechanism if and only if it satisfies ${ }^{1 \mathrm{~s}}$.

Furthermore, we can see that the class of SCCs Nash-implementable by s-mechanisms is not proper subset of the class of Nash-implementable SCCS.

Lemma. ${ }^{1 \mathrm{~s}}$ is equivalent to ${ }^{1}$.

P roof. From Proposition 1 and Moore and Repullo (1990), it is suc cient to show that ${ }^{1 \mathrm{~s}}$ implies $^{1}$. Let an SCC F satisfy ${ }^{1 \mathrm{~s}}$. Then, by Theorem, this $\mathrm{F}$ is Nash-implementable by an s-mechanism, so that it is Nash-implementable. Thus, by Moore and Repullo (1990), F satisfies ${ }^{1}$.

From Theorem and Lemma, the following corollary holds:

Corollary. An SCC F is Nash-implementable by an s-mechanism if and only if it is Nash-implementable.

\section{Concluding Remarks}

In this paper, we deal with the informational ed ciency issue pertaining to Maskin's Theorem (Maskin, 1999). We focus on s-mechanisms in which each agent reports to the planner her own preference and her neighbor's preference 
solely, in addition to a feasible social outcome and an integer. We introduce a new condition, labelled Condition ${ }^{1 \mathrm{~s}}$, which fully characterizes the class of SCCs Nash-implemantable by s-mechanisms. Surprisingly, Condition ${ }^{1 \mathrm{~s}}$ is equivalent to Condition ${ }^{1}$. This has two important implications for Nash implementation. First, the class of Nash-implementable SCCs is equivalent to the class of SCCS Nash-implementable by s-mechanisms. Second, even though our condition is stated in terms of the existence of certain sets, it can easily be checked in practice by the agorithm provided by Sjöström (1991).

Note that our results are in line with other well known results of Nash implementation in economic environments. In particular, the equivalent relationship between Nash implementation by s-mechanism and Nash implementation by canonical mechanisms in general social choice environments is analogous to the equivalent relationship between Nash implementation by natural allocation mechanisms and Nash implementation by natural quantity ${ }^{2}$ mechanisms (Saijo et al, 1996). M oreover, Tatamitani (2001) provides a full characterization of Nash implementation by self-relevant mechanisms, which together with this paper indicates that a further reduction of the strategy spaces of s-mechanisms drastically decreases the class of Nash-implementable SCCs. This is parallel to the case of natural implementation in economic environments, in which the class of SCCS Nash-implementable by natural quantity mechanisms is much smaller than the Nash-implementable ones by natural quantity ${ }^{2}$ mechanisms.

In contrast, whenever we modify the standard framework of implementation theories to a more practical framework by introducing an element of perspectives from behavioral economics, the above mentioned relationship obtained in this paper would not preserve. To be more specific, Matsushima (2008) and Dutta and Sen (2009) introduce the notion of a partially honest agent as an element of behavioral economic perspectives, and consider Nash implementation problems with an assumption that there is at least one partially honest agent who not only has the standard self-interested preference on consequences but also has an intrinsic preference on truth-telling behavior. In such a framework, the equivalent relationship between $\mathrm{Nash}$ implementaion and Nash implemantaion by s-mechanisms no longer holds, as Lombardi and Yoshihara (2010) show. This suggests that the equivalent relationship indispensably relies on the standard assumption of self-interested behaviors. 


\section{R eferences}

Danilov, V. (1992): Implementation via Nash equilibria, Econometrica 60, 43-56.

Dutta, B ., and Sen, A. (1991): A necessary and suc cient condition for twoperson Nash implementation, Review of Economic Studies 58, 121-128.

Dutta, B., and Sen, A. (2009): Nash implementation with partially honest individuals, mimeo.

Hurwicz, L. (1960): Optimality and informational ec ciency in resource allocation processes. In: Arrow, K.J ., Karlin, S., Suppes, P. (eds), Mathematical M ethods in the Social Sciences. Stanford University Press, 27-46.

Lombardi, M. and N. Yoshihara (2010): On Nash implementation with partially honest agents: Almost necessary and suф cient characterizations, mimeo.

Maskin, E. (1999): Nash equilibrium and welfare optimality, Review of E conomic Studies 66, 23-38.

Matsushima, H. (2008): Role of honesty in full implementation, J ournal of E conomic Theory 139, 353-359.

Moore, J., and Repullo, R. (1990): Nash implementation: A full characterization, Econometrica 58, 1083-1100.

Saijo, T. (1988): Strategy space reduction in Maskin's theorem: suф cient conditions for Nash implementation, E conometrica 56, 693-700.

Saijo, T., Tatamitani, Y., and Yamato, T. (1996): Toward natural implementation, International E conomic Review 37, 949-980.

Sjöström, T. (1991): On the necessary and suф cient conditions for Nash implementation, Social Choice and W elfare 8, 333-340.

Tatamitani, Y . (2001): I mplementation by self-relevant mechanisms, J ournal of Mathematical E conomics 35, 427-444.

Yamato, T. (1992): On Nash implementation of social choice correspondences, Games and Economic B ehavior 4, 484-492. 